\title{
KANT: CONCIENCIA REFLEXIVA Y PROCESO HUMANIZADOR*
}

Dulce María Granja**

A la memoria de Milagros M. Mier G.

Los fieles discípulos de Kant

no son los que repiten su filosofía

sino los que piensan por cuenta propia.

El día 12 de febrero se cumplieron doscientos años de la muerte de Kant y en las principales universidades del mundo se conmemorará, a todo lo largo de este 2004, ese fallecimiento.

Como un modesto homenaje a ese gran filósofo, deseo evocar su figura y su obra presentando el bosquejo de un retrato que nos permitiera contestar a la pregunta ¿quién fue Immanuel Kant? y nos proporcione algunos elementos para ofrecer una respuesta a la pregunta ¿qué es el idealismo trascendental?

Quizá una buena manera de empezar ese retrato sea refiriéndome a una famosa entrevista realizada por el filósofo inglés contemporáneo

* La primera parte de este artículo fue leída en la conferencia inaugural del curso "El pensamiento de Kant" en la cátedra extraordinaria "Maestros del Exilio Español” pronunciada el 25 de febrero de 2004 en la Facultad de Filosofía y Letras de la UNAM y el 26 de abril en la Sala de conferencias del ITAM; la segunda parte el 3 de mayo en la Biblioteca Gómez Morín, también del campus Río Hondo.

** Centro de documentación kantiana, UAM-I. 
DULCE MARÍA GRANJA

Brian Magee $^{1}$ a un compatriota suyo, reputado conocedor de la filosofía kantiana y vice-rector de la universidad de Oxford: Sir Geofrey Warnock. Quizá sea ésta una buena manera de iniciar tal retrato porque, como es bien sabido, los ingleses en general no se han caracterizado por profesar especial admiración hacia los filósofos alemanes ya que en su isla ellos mismos han tenido excelentes filósofos.

En aquella famosa entrevista, Magee afirma: "Durante varias generaciones los estudiosos de la filosofía han considerado a Immanuel Kant el filósofo más importante después de los antiguos griegos” y pregunta: “¿a qué cree usted que se deba el que Kant esté considerado tan excelentemente?”

Warnock responde diciendo:

Yo mencionaría dos cualidades para justificar la gran posición que Kant ocupa en la filosofía. Creo que fue extraordinariamente profundo, en el sentido de que fue capaz de ver un problema intelectual en algo que hasta entonces se había considerado poco importante. Tenía una capacidad extraordinaria para ver dónde estaban los problemas -y ése es uno de los dones filosóficos más grandes y fundamentales que se pueden tener-, era capaz de reconocer y resolver un problema donde nadie más lo veía. Y la otra cualidad -y esto tal vez tenga relación con su profesionalismo académico- es que tenía una gran capacidad para relacionar entre sí argumentos, para ver cómo encajaban, cómo lo que dice sobre un determinado tema puede repercutir en lo que ha dicho en algún otro lugar acerca de otra cosa. Era muy concienzudo y muy metódico en ese sentido; no hay nada de desorden, descuido ni improvisación en su obra. Da la sensación de que toda su gran producción está bajo control. Tengo

${ }^{1}$ Realizada para una serie de televisión que la BBC transmitió por primera vez en 1987. Basándose en dicha serie Magee redactó posteriormente un libro traducido al castellano por la editorial Cátedra de Madrid en 1995 con el título Los grandes filósofos. Para dicha entrevista, véanse p. 181 s. de esa edición. 
que decir que hace que escritores como Locke y Berkeley, incluso Hume, parezcan principiantes, a pesar de que fueron sin duda excelentes.

Este reconocimiento, procedente de un pensador británico perteneciente a una corriente filosófica que está lejos de considerarse seguidora ferviente del sabio de Königsberg, nos invita a explorar esos dos rasgos destacados por Warnock.

En este trabajo intentaré conectar recíprocamente esos dos rasgos uniéndolos en la persona de Immanuel Kant al tratar de responder la pregunta ¿quién fue Immanuel Kant? Así, el trabajo constará de dos partes. En la primera buscaré ahondar en el primero de esos rasgos procurando sumergirme en la fuente de la que pienso que él emana. Dejaré para la segunda parte del trabajo el examen del segundo de esos rasgos, cuando trataré de responder a la pregunta ¿qué es el idealismo trascendental? Veremos, por último, que la sección final tanto de la primera como de la segunda parte concluyen en una y la misma idea: la insistencia en la conciencia reflexiva como motor del proceso humanizador.

\section{I}

\section{¿Quién fue Immanuel Kant?}

\section{El hombre y la obra}

Trataré de responder la pregunta ¿quién fue Immanuel Kant? haciendo un breve recuento biográfico ${ }^{2}$ y centrándome en el primero de esos dos rasgos que pueden considerarse como los centrales de su sistema.

Immanuel Kant nació en la ciudad de Königsberg, el 22 de abril de 1724 y murió ahí mismo el 12 de febrero de 1804, cuando estaba por

${ }^{2}$ Una muy detallada biografía sobre Kant es la que publicó en 2001 Manfred Kuehn bajo el título Kant en Cambridge University Press. Esta biografía ha sido traducida al castellano por la editorial española Forte Acento, 2003, Madrid. 
DULCE MARÍA GRANJA

cumplir los ochenta años. Situada sobre el río Pregel, a poca distancia del Mar Báltico, Königsberg era la capital de Prusia Oriental, la más remota de las provincias alemanas, alejada de la Europa 'culta', situada en la frontera con Rusia y Finlandia. No obstante esa lejanía, Königsberg era una de las cuatro ciudades alemanas más importantes, un cruce de caminos que comunicaba comercialmente la Europa oriental con los más lejanos puertos marítimos. En la época que nace Kant, Königsberg tiene una población de poco más de 40,000 habitantes. Immanuel fue el cuarto de los nueve hijos de una familia modesta de artesanos, matrimonio formado por Anna Regina Reuter (1697-1737) y el maestro sillero Johann Georg Kant (1683-1746).

A los ocho años de edad, Kant ingresa al Collegium Fridericianum, institución dirigida por el jefe de la corriente pietista en Königsberg, Franz Albert Schultz, párroco, doctor en teología y profesor en la Universidad. Durante los ocho años que permaneció en el Collegium adquirió sólido conocimiento de las lenguas antiguas y las humanidades clásicas y se familiarizó con la literatura de los clásicos latinos. Se despertó en él gran aprecio a los poetas y amor por las bellas artes. Un acontecimiento importante en la vida del joven Kant fue la inesperada muerte de su madre, la noche de navidad de 1737, cuando él contaba trece años de edad.

En septiembre de 1740 a 16 años de edad, Kant ingresa a la Universidad de su ciudad natal donde es introducido por Martin Knutzen (1713-1751), discípulo de Alexander Baumgarten y profesor extraordinario de lógica y metafísica, en el conocimiento de la física de Newton. También asiste a las clases de teología de Franz Albert Schultz.

En 1746 muere su padre y Kant con 22 años, tiene que empezar a ganarse la vida, para lo cual se emplea como preceptor de los hijos de las familias nobles residentes en la campiña cercana a Königsberg, especialmente en la casa de la condesa von Kayserling. Años más tarde, al evocar esta época el filósofo recordará con agrado que si bien los hijos de la noble señora fueron sus discípulos, él fue, a su vez, discípulo de la condesa en el arte de la buena conversación. Los ocho años de este tiempo de preceptorado, que va desde 1748 hasta 1754, fue 
una época de recogimiento y estudio: Kant se hacía traer de la ciudad libros y revistas y estaba al corriente del pensamiento contemporáneo, sobre todo en lo tocante a las teorías científicas y los problemas filosóficos planteados por ellas.

En 1755 regresa a la ciudad y da inicio a su carrera docente, obtiene el doctorado y la habilitación como docente libre. Desde ese momento, cuando Kant cuenta con 30 años, ejercerá ininterrumpidamente la enseñanza de la filosofía durante más de cuarenta años, pues impartió su última clase el 23 de julio de 1796, a los 72 años de edad. De hecho, Kant fue el primer gran filósofo de la era moderna que se dedicó profesionalmente a la enseñanza de la filosofía en la universidad. Antes de él, Descartes, Spinoza, Leibniz, Locke, Berkeley, Hume, no habían enseñado filosofía. Ni tampoco la enseñaron la gran mayoría de los filósofos importantes del siglo posterior a Kant, el siglo XIX, con la excepción de Hegel. Así, Schopenhauer, Nietzsche, Kierkegaard, Marx, Stuart Mill, no fueron filósofos académicos. Durante este período como docente libre, Kant daba muchas horas de clase (parece que algún semestre llegó a impartir hasta veinticuatro o veintiséis horas semanales) y sobre los temas más variados: lógica, metafísica, ética, pedagogía, antropología, mecánica, geografía física, geometría y trigonometría, etc. ${ }^{3}$

Kant tenía un buen número de alumnos, y Herder, quien escuchó sus lecciones de 1762 a 1764 nos ha dejado la siguiente descripción de él en sus Cartas para la elevación de la humanidad ${ }^{4}$ publicadas en 1797, 35 años después de su encuentro con el pensador de Königsberg:

Tuve la fortuna de tener como profesor a un gran filósofo, a quien considero un verdadero maestro de la humanidad. Este hombre tenía en aquel entonces la animación propia de un muchacho,

${ }^{3}$ El catálogo completo de los cursos impartidos por Kant puede consultarse en Emil Arnoldt, Gesammelte Schriften, vol. 2 "Kritische Excurse im Gebiete der Kantforschung”, 1909, Berlín, Schöndörffer.

${ }^{4}$ Cfr. Johann Gottfried Herder, Briefe zur Beförderung der Humanität, 79. Véase Sämtliche Werke, 1967, edición de Bernhard Suphan, vol. XVII, Georg Olms, Hildesheim, p. 404. 
DULCE MARÍA GRANJA

cualidad que según parece no desapareció en su madurez. Su amplia frente, hecha para pensar, era la cuna de un gozo y una amenidad inagotable; de sus labios brotaba un discurso pleno de inteligencia. Tenía siempre a su servicio las anécdotas, el humor y el ingenio, de modo que sus clases resultaban siempre tan educativas como entretenidas. En sus lecciones se examinaban las últimas obras de Rousseau con un entusiasmo sólo comparable con la acuciosidad aplicada al estudio de las doctrinas de Leibniz, Wolf, Baumgarten o Hume, por no mencionar la lucidez derrochada al explicar las leyes naturales concebidas por Kepler y Newton. Ningún descubrimiento era minimizado por él para explicar mejor el conocimiento de la naturaleza y el valor del ser humano. La historia de la humanidad, de los pueblos y de la naturaleza, las ciencias naturales, la matemática y la experiencia eran las fuentes con las que este filósofo animaba sus lecciones y su trato. Nada digno de ser conocido le era indiferente. Ninguna secta, ningún provecho personal y ninguna ambición ensombrecieron su celosa pasión por dilucidar y dar a conocer la verdad. Sus alumnos no recibían ninguna consigna más que la de pensar por cuenta propia; nada le fue mas ajeno que el despotismo. Este hombre, cuyo nombre invoco con la mayor gratitud y el máximo respeto, no es otro que Immanuel Kant.

Se han escrito numerosos chistes acerca del hecho de que Kant nunca salió de su ciudad natal, también a propósito de su extraordinaria puntualidad y de la absoluta monotonía de sus hábitos diarios, que llegaban al extremo de que los habitantes de la ciudad podían poner los relojes en hora al ver pasar al filósofo frente a sus ventanas. No se casó, ni se le conoció amante alguna y aparentemente su vida careció de incidentes. ${ }^{5}$

${ }^{5}$ Véase Jean-Baptiste Botul, La vida sexual de Kant, Colección "Pequeños Grandes Ensayos”, 2003, México, UNAM. 
Sin embargo, las tres biografías que escribieron contemporáneos de $\mathrm{Kant}^{6}$ en vida de éste tienen el mérito de apartarse de esos caminos trillados. Asimismo, nos relatan que la celebridad no llegó a Kant sólo después de su muerte; que era sociable, jovial, elegante en el vestir, ingenioso en la conversación y que sus clases en su Universidad natal eran famosas por su brillantez. Kant estaba lejos de ser un tímido profesor provinciano y su nombre era conocido fuera de las fronteras de Alemania, pues hacia 1769, a sus 45 años, ya había publicado más de veinte relevantes trabajos.

Para ilustrar la importancia y alcance de las obras de Kant correspondientes a esta etapa, baste mencionar sólo una de ellas. Kant contaba con 31 años cuando publicó en 1755 su Allgemeine Naturgeschichte und Theorie des Himmels (Historia general de la naturaleza y teoría del cielo), sin duda la obra científica más notable que él escribiera durante el período precrítico. Uno de los grandes méritos de este erudito y original trabajo es que propone por primera vez la hipótesis nebular del origen del sistema solar, 41 años antes de que la divulgara Laplace en su Système du monde (París, 1796).

Estoy persuadida de que no es exagerado decir que si esta obra hubiera sido publicada en París o en Londres y no en Königsberg, Kant inmediatamente habría alcanzado la fama. Por desgracia el editor,

${ }^{6}$ En 1804, pocos meses después de la muerte de Kant, vieron la luz en Königsberg simultáneamente las tres biografías más importantes del filósofo, que junto con su correspondencia personal constituyen el manantial más completo de datos fidedignos que poseemos sobre la personalidad y la vida del pensador prusiano. Casualmente, los tres biógrafos fueron todos ellos pastores protestantes: Reinhold Bernhard Jachmann, Ludwig Ernst Borowski y Ehregott Andreas Christoph Wasianski. Los tres habían conocido a Kant personalmente: fueron alumnos y amigos suyos, pasearon y conversaron con él, compartieron su mesa e incluso -especialmente Wasianski- lo asistieron en los últimos días de su vida, cuando Kant prácticamente no podía valerse por sí mismo. Las tres biografías fueron editadas por Nicolovius y llevaban el título genérico Über Immanuel Kant, pero cada uno de esos tres trabajos tiene un título específico. 
DULCE MARÍA GRANJA

Johann Friederich Petersen, quebró durante la impresión de la obra y sus propiedades fueron clausuradas, por lo cual la obra de Kant permaneció prácticamente desconocida por sus contemporáneos. En 1755 encontramos solamente una reseña de la obra en un periódico de Hamburgo y en 1756 una más en un periódico de Königsberg. En esta obra Kant también considera la posibilidad de vida en otros planetas.

El período que se ha conocido como 'precrítico', y al que Kant se refería como sus ‘años de magisterio’ se caracteriza por una fuerte actividad docente aunada a una franca apertura social y mundana. Fue ésta una época de juventud, grata y laboriosa, a la que años más tarde el filósofo se referirá como 'la más satisfactoria de mi vida'.

Ciertamente Kant sigue padeciendo limitaciones materiales y exceso de trabajo académico, pero su juventud y disponibilidad para adaptarse le permiten superar esos obstáculos. Si lo característico de los años posteriores de la vida de Kant, especialmente los de gestación y exposición de la filosofía crítica, será la concentración de todas sus energías vitales e intelectuales en una meta, en esta etapa, en cambio, Kant se entrega al trato social y a la anchura de la vida. Rink nos informa que durante estos años Kant "pasaba fuera de casa, en compañía de otras personas, buena parte de las tardes y las noches e incluso tomaba parte no pocas veces en los juegos; cuando no estaba convidado, comía fuera de casa, en el restaurante, en una mesa a la que se sentaban también otras personas cultas". ${ }^{8}$ Así, Kant no rechaza invitaciones y frecuenta abiertamente los ambientes no académicos, los salones aristocráticos y la mesa de oficiales y funcionarios. Pero sobre todo, en este período Kant inicia un vínculo que perdurará durante toda su vida con algunos comerciantes y hombres de negocios de la colonia inglesa, muy numerosa e influyente en Königsberg, especialmente después de la Guerra de los siete años, en cuya victoria será decisiva la ayuda inglesa.

${ }^{7}$ Cfr. la carta que Kant envía a Lagarde con fecha del 25 de marzo de 1790.

${ }^{8}$ Friedrich Theodor Rink, Ansichten aus I. Kants Leben, 1805, Königsberg, p. 22. 
En 1770 quedó vacante la cátedra de lógica y metafísica. Kant concursó por dicha cátedra y pudo así, a los 46 años, llegar a ser profesor ordinario. Teniendo su primer sueldo fijo y seguro pudo disminuir un poco las horas de clase y dedicarse más libremente al trabajo personal. La década que se conoce como 'década del silencio' y que corre de 1770 a 1781, año en el que apareció la primera edición de la Crítica de la razón pura, fue de intensa meditación; en este período, a diferencia de lo que hiciera antes, Kant no publicó casi nada y se dedicó enteramente a la elaboración de su sistema.

La década que corre de 1780 a 1790, período relativamente corto en la vida de Kant, fue especialmente fecunda y creativa. Además de numerosas obras de menor dimensión, ${ }^{9}$ en rápida sucesión se publican las grandes obras fundamentales de la filosofía kantiana. Así en 1781, pocos días después de que Kant cumpliera 57 años, aparece la Crítica de la razón pura; en 1783 los Prolegómenos; en 1785 la Fundamentación de la metafísica de las costumbres; en 1786 los Primeros principios metafísicos de la ciencia de la naturaleza; en 1787 la segunda edición -con sus numerosas e importantes modificaciones-de la Crítica de la razón pura; en 1788 la Crítica de la razón práctica y en 1790 la Crítica de la facultad de juzgar. En esta década Kant extiende su reflexión crítica a los ámbitos especulativo, práctico, estético y teleológico; incluso podría decirse que al terminar ese período Kant concluyó su obra propiamente crítica. En adelante la reflexión y el método kantiano se aplicará a los problemas de la religión y la historia, el derecho y la antropología, la lógica y la pedagogía, pero en ninguna de

${ }^{9}$ E. g.: En 1784 se publica Idea de una historia universal en sentido cosmopolita; y Respuesta a la pregunta ¿qué es la ilustración? En 1785 aparece en la Allgemeine Litteraturzeitung la reseña del libro de Herder "Ideas sobre la filosofía de la historia de la humanidad"; y la Berlinische Monatsschrift publica tres artículos de Kant: "Sobre los volcanes de la Luna", "Sobre la ilegalidad de la falsificación de libros” y "Sobre la definición del concepto de raza humana”. En 1786 aparecen numerosas publicaciones entre las que se destacan: Probable inicio de la historia humana y Qué es orientarse en el pensamiento. 
DULCE MARÍA GRANJA

las obras nuevas se presentarán rupturas con los trabajos fundamentales de la década de los ochenta.

A medida que pasaban los años, crecía el renombre del filósofo dentro y fuera de su ciudad. Por seis ocasiones fue Decano de su facultad, dos veces fue Rector de la Universidad y fue también miembro permanente del Senado universitario. Fue asimismo miembro de la Academia de Berlín, de la de San Petersburgo y de la de Viena. Kant fue un hombre profundamente honesto. No buscó otro medio para vivir fuera de su trabajo recogido, tenaz, riguroso y perseverante. No se dejó fascinar por el dinero ni por la fama y su filosofía resuma libertad de espíritu y amor a la verdad.

\section{Proceso educativo e identidad personal.}

He dicho que Kant fue el primer gran filósofo de la era moderna que se dedicó profesionalmente a la enseñanza de la filosofía en la universidad y que tanto antes como después de él la mayoría de los filósofos importantes no enseñaron filosofía. En la era moderna, sólo al llegar al siglo XX, encontramos que casi todos los filósofos importantes son académicos. Yo considero que esta profesionalización es inevitable, entre otras razones, por lo que diré enseguida refiriéndome a lo que Kant, el primero de los grandes profesores, consideró como la esencia del proceso educativo. ${ }^{10}$

La Universidad es hoy en día la promotora por excelencia del humanismo y la cultura porque una de sus tareas fundamentales es la educativa, es decir, la tarea de formación de seres humanos mediante el desarrollo de la actitud crítica. De hecho, podría decirse que el proceso educativo es un proceso humanizador, es decir, un proceso de cons-

${ }^{10}$ Un examen más detallado de la concepción kantiana del proceso educativo puede verse en Granja, D. M., "Sobre las Lecciones de Pedagogía de Immanuel Kant: consideraciones en torno a la filosofía kantiana de la educación”, en Signos Filosóficos, Revista del Departamento de Filosofía de la UAM-Iztapalapa, vol. II, Núm. 3, enero-junio 2000, p. 74-87. 
trucción de nuestra propia identidad personal mediante el ejercicio de la conciencia reflexiva. Sin duda, corresponde a Kant el mérito histórico de haber ofrecido por primera vez una sólida argumentación capaz de dar cuenta y razón de por qué la dignidad del ser humano radica en su capacidad de construir su propia identidad, en la libertad para forjar su personalidad propia mediante el desarrollo de la actitud crítica. En efecto, Kant nunca confundió el quehacer personalísimo y propio del ser humano con la incorporación a un determinado grupo donde se garantice una verdad definitiva.

Ya en la antigüedad clásica Sócrates nos enseñó que una de las tareas esenciales del filósofo es la formación de seres humanos, la educación por medio de la transmisión de una actitud crítica. Si a Descartes se le llama ‘el padre de la filosofía moderna', hay que llamar a Kant su pedagogo. El padre da la vida al hijo, pero el pedagogo lo educa y ésta es la función de Kant en la historia.

Según vimos, Warnock consideró que uno de los principales méritos de Kant es que tiene una capacidad extraordinaria para hacer que una enorme cantidad de ideas encajen de un modo sistemático, global, armonioso, integral ('holístico', como suele decirse hoy). Por eso creo que es importante tratar de remontarnos a lo que me parece fue la preocupación más amplia y fundamental de Kant y que verdaderamente dio lugar a todo su sistema filosófico.

Kant pensó que hay un núcleo de problemas que podrían calificarse como cardinales cuya solución constituye el objetivo final al cual la razón humana encamina todos sus esfuerzos; situaciones frente a las cuales todos los demás problemas poseen el valor de simples medios; ante los cuales es imposible simular indiferencia. ${ }^{11}$

Para Kant estos problemas eran: la existencia de Dios, la libertad de la voluntad y la inmortalidad del alma.

Según Kant en estos tres temas radica la clave de la respuesta a tres preguntas que resumen todos los intereses y afanes de la razón. En mi opinión ésas son las tres preguntas radicales que Kant trató de resolver:

${ }^{11}$ Cfr. KrV, A 795/B823 s. Véase también KrV, A X. 
DULCE MARÍA GRANJA

¿Qué puedo saber? ¿Qué debo hacer? ¿Qué puedo esperar? Y que, decía Kant, se pueden resumir, a su vez, en una sola: ¿Qué es el hombre? De hecho, me atrevería a afirmar que si hoy estuviera aquí Kant y le preguntáramos: Profesor Kant, ¿qué es la filosofía?, nos respondería: La disciplina que se encarga de responder tres preguntas fundamentales: ¿Qué puedo saber? ¿Qué debo hacer? Y ¿Qué puedo esperar? ${ }^{12}$

Así pues, en el núcleo de la antropología filosófica que Kant nos ofrece está el tema crucial de las relaciones entre conocer, creer y obrar. ${ }^{13}$ Me centraré esta tarde en la segunda pregunta: ¿Qué debo hacer?

En efecto, parece que existe un conflicto entre los conocimientos de las ciencias de la naturaleza y nuestras creencias éticas y religiosas fundamentales. Las ciencias naturales nos enseñan que todo lo que ocurre en la naturaleza está determinado por sucesos anteriores. O en otras palabras: en todos los acontecimientos del mundo natural encontramos que siempre existe una ley en base a la cual se puede decir que, dadas las condiciones previas, lo que ha ocurrido es lo único que podía haber ocurrido.

Pero, para el gran maestro de Königsberg no sólo somos seres pertenecientes al reino de la naturaleza gobernado por el mecanicismo ineluctable. Además somos seres racionales, es decir, seres con una conciencia reflexiva que nos lleva más allá del reino de la naturaleza para confrontarnos con el reino del deber. Sólo un animal que esté dotado de razón se hace cuestión de su libertad y se plantea la pregunta ¿qué debo hacer?

Esta pregunta nos introduce en un orden de cuestiones de vital importancia para el ser humano: el orden moral. Y digo de vital importancia porque nada en la vida humana es más real que tener que tomar decisiones 'según la idea de libertad'. Esto significa que el ser humano no es

${ }^{12}$ Cfr. KrV A 805/833. Véase también el apartado III de las Lecciones de Lógica.

${ }^{13}$ Cfr. El canon de la razón pura, sección tercera, A820/B848-A831/B859. Véase también A801/B829. 
un mero objeto entre otros, sino un sujeto de cuya acción libre depende la configuración de la personalidad propia, pues en cada decisión el ser humano se pone en juego a sí mismo. Detengámonos brevemente en esta idea kantiana según la cual el proceso educativo es el proceso de construcción de la propia identidad.

Para Kant es un hecho innegable que la mayor parte de los seres humanos tenemos convicciones morales que nos resulta imposible ignorar aunque lo deseemos. Es un hecho innegable que constantemente proferimos juicios en los que hacemos una evaluación moral de nuestra conducta o de la conducta de nuestros semejantes. Así, por ejemplo, decimos:

a) ese funcionario es corrupto, aquel otro es honesto

b) esa periodista es veraz, aquella otra falsea la información

c) ese empresario es indiferente ante la pobreza ajena, aquel otro no lo es.

¿Qué está implícito en estos tres juicios? Que el funcionario debe ser honesto, que la periodista debe ser veraz y que el rico empresario no debe ser indiferente ante la necesidad ajena. Es decir: está implícito el que la moralidad nos hace exigencias. terminantes, sin excepción, inexcusables, no sujetas a condición alguna.

Kant se pregunta: ¿tenemos derecho a tener convicciones morales? o, en otras palabras: ¿qué justifica las exigencias morales? Y se esforzará por presentarnos una respuesta. Llamaré a esta pregunta la pregunta normativa o la pregunta por la normatividad. ${ }^{14}$

Para que las convicciones morales tengan validez, o incluso, significado, para que los conceptos morales básicos como bueno, malo, justo, injusto, etc., tengan validez o significado, es necesario que tengamos libertad de elección, en otras palabras, es necesario que podamos ejercer nuestra voluntad, pues de no ser así cualquier intento de evalua-

\footnotetext{
${ }^{14}$ Véase Cristine Kosgaard, Las fuentes de la normatividad, 2000, México, UNAM, p. 19-165.
} 
DULCE MARÍA GRANJA

ción moral es inútil y carente de sentido (dicho de manera descarnada: la vida humana sería una farsa, una comedia: permanentemente estaríamos actuando a ser 'buenos' o ser 'malos').

Esto significa que la perspectiva o posición desde la que surge la pregunta normativa es la posición de primera persona, la perspectiva del agente que exige una justificación de las exigencias de la moralidad.

En otras palabras: la pregunta normativa sólo se puede plantear (y sólo se puede resolver) desde la perspectiva de la primera persona.

La posición de la primera persona es la posición del yo personal que desde dentro de sí tiene que decidir si actúa de un modo o si actúa de otro, es la posición en la que se encuentra nuestro yo cuando reflexionamos sobre qué hacer (en nuestros ejemplos: la posición de la primera persona es la posición de la conciencia interior del funcionario que decide entre ser corrupto o ser honesto; es la posición de la periodista que en su fuero interno toma la decisión de ser veraz o de mentir; es la posición del tribunal de la conciencia del rico industrial en el cual hace la elección de ser solidario o de ser insensible ante la pobreza).

Así pues, podríamos decir que libertad es la capacidad de actuar (de un modo o) de otro modo. Esta capacidad sólo se descubre en la reflexión que hace un yo desde su perspectiva de primera persona. Esta libertad no es una propiedad que puedan ver todos aquellos que estudian las deliberaciones del agente desde fuera de éste, desde la perspectiva externa de la tercera persona.

Regresando a nuestros ejemplos, podemos hablar del periodista fulano en tercera persona intentando explicar por qué, por ejemplo, falseó cierta información (difamó, calumnió, destruyó el buen nombre de alguien), atribuyendo su conducta a factores y circunstancias naturales o sociales que lo obligaron a actuar como lo hizo (una presión laboral, una dificultad económica, un compromiso social, un resentimiento o una venganza).

Sin embargo, no podemos hacer esto mismo cuando cada uno de nosotros habla en nombre propio, refiriéndose a sí mismo en primera persona. Sería totalmente inadmisible que yo dijera: "no puedo actuar de otra manera”, o "las circunstancias me obligan a actuar como lo 
hago” pues estaría sencillamente dimitiendo de mi condición de persona para pasar a considerarme como una cosa más, sometida como el resto de las cosas a la forzosa ley de causalidad; estaría pretendiendo renunciar a la humana carga de ser dueña de mis actos. Y eso (que Jean Paul Sartre llamó la 'mala fe') es lo más indigno que un ser humano puede hacer, pues equivale a renunciar a su condición de ser humano, a situarse por debajo de su propia dignidad.

En realidad nadie puede decir "las circunstancias me obligan a actuar como lo hago" sin caer en contradicción, porque al decir tal cosa, ya está eligiendo un modo de actuación, sólo que prefiere auto engañarse y no reconocerlo, intenta eximirse tramposamente del riesgo de la libertad. En realidad, no podemos dejar de ser libres. Estamos, recordando nuevamente a Sartre, 'condenados a ser libres' .

Al ser humano se le plantea la pregunta ¿qué debo hacer? Y necesita contestarla. Y para contestarla no le basta con haber respondido a la pregunta sobre "qué es lo que puede conocer", es decir, no le basta con la ciencia. En efecto, la ciencia tanto natural como social, le puede proporcionar indicaciones muy útiles sobre las condiciones en que tiene que elegir un curso de acción u otro y sobre las consecuencias de uno y otro, pero no puede elegir por él. La decisión es suya y sólo suya.

Kant define a la voluntad como razón práctica. Esto significa que no puede concebirse que la voluntad elija y actúe sin razón alguna. Dado que las razones se derivan de principios, la voluntad debe tener principios. Lo que Kant trata de hacer en su filosofía moral es extraer del concepto de racionalidad los principios esenciales de la moralidad. Lo esencial de cualquier agente sobre el que se pueda hablar o pensar desde el punto de vista de la moralidad es que debe ser racional, es decir, capaz de buscar razones, de presentar y de exigir razones a favor o en contra de hacer esto o aquello. Kant argumenta haciendo ver que los requisitos esenciales de la moralidad se encuentran en el mismo concepto de racionalidad.

Éste me parece que es un punto enormemente importante pues significa que si hay una actividad que ha de ser objeto de escrutinio racional 
DULCE MARÍA GRANJA

público, que debe ofrecer razones que han de ser sometidas a evaluación racional, es la actividad moral. En efecto, nuestras razones son públicas en esencia; en otras palabras: es una contradicción hablar de una ‘razón' que no puede ser objeto de discusión pública.

Por otra parte, si la voluntad debe ser libre, esto significa que no puede imponérsele desde fuera ningún principio o ley. Kant concluye que la voluntad debe ser autónoma, es decir, debe tener su propia ley o principio pues si esta ley o principio se le impusiera desde fuera, la voluntad ya no sería libre. La voluntad debe hacer su propia ley, en otras palabras: la voluntad debe ser una ley para sí misma. ${ }^{15}$

Así llegamos a la pregunta que constituye el corazón del problema: ¿cómo puede la voluntad hacer una ley y no otra? Dicho en palabras muy llanas. ¿De cualquier dictado de mi voluntad puedo derivar una razón para obrar? La respuesta de Kant es rotunda: no cualquier dictado de la voluntad puede proporcionar razones para obrar y verse, entonces, constituido en ley de la voluntad.

Así pues, la pregunta ¿cómo puede la voluntad hacer una ley y no otra? Se ha transformado en la siguiente: ¿cuál es el criterio que nos permite determinar si un dictado de la voluntad proporciona razones para obrar?

Kant llama a este criterio imperativo categórico y sostiene que tiene tres formulaciones básicas que se implican recíprocamente entre sí; yo sólo citaré ahora la segunda de ellas, la llamada fórmula de la humanidad, la cual reza así: “Obra de modo tal que en la máxima de tu voluntad consideres a la humanidad, tanto en tu persona como en la de los demás, siempre como un fin en sí mismo y nunca como un mero medio." 16

Esta concepción del principio de la moralidad que Kant propone exige que la vida humana se desarrolle en un reino de los fines, es decir, en una comunidad abierta e incluyente en la que todos los seres huma-

${ }^{15}$ Cfr. Crítica de la razón práctica, Ak. Aug., vol. v, 31-33.

${ }^{16}$ Véase la Fundamentación a la Metafísica de las Costumbres, Ak. Aug., IV, 421, 428 s, 436 s, 440 y 446. 
nos nos hemos de reconocer como libres e iguales (es decir: como capaces de autodeterminarnos y como universalmente legisladores). En realidad, podría decirse que la moralidad es simplemente la forma que toma la vida humana. No hay forma de vida humana que no sea la forma moral de la vida.

En resumen, podríamos decir que la ley moral es la ley que se extiende sobre todo ser racional, es la ley que impera en lo que Kant llamaba el 'Reino de los Fines', y que yo podría traducir como la República de todos los seres racionales, (o en otras palabras, un sistema cooperativo factible en el que pueda integrarse todo ser humano).

En esta concepción de la ley moral que Kant propone no sólo está en juego la posibilidad de una comunidad humana en la que sus integrantes tienen dignidad, no precio. También está en juego la concepción de nuestra propia identidad personal, pues valorar nuestra propia humanidad implica, conlleva o supone (según lo dicho anteriormente) valorar la de los otros. En efecto, valorar nuestra propia humanidad equivale a tener identidad moral. Tener 'identidad moral' es ejercer nuestra capacidad racional, nuestra conciencia reflexiva que cuestiona y evalúa los principios mismos de la moralidad, las formas de vida, los valores y los sistemas de normas que nos ha transmitido la tradición. Lo que aquí está en juego es la concepción que tenemos de nosotros mismos. Por esta concepción que tenemos de nosotros mismos nos valoramos, le encontramos sentido a la vida y consideramos que nuestras acciones merecen emprenderse. Las concepciones de nosotros mismos a las que más importancia les concedemos son aquellas que dan lugar a obligaciones incondicionales, pues contravenirlas equivale a perder la integridad y, por ende, a perder la identidad. Esto equivale a estar muerto o algo peor aún. Pero, ¿qué podría ser peor que estar muerto?: estar vivo y no ser uno mismo. Así pues, la ley moral encarnaría, en palabras de Sócrates, “aquello por lo cual la vida vale la pena de ser vivida”.

Considero que la fuerza de la obra de Kant radica precisamente en ser un ejemplo estimulante y eficaz de reflexión crítica y autonomía, que no sólo nos recuerda que "nada es tan difícil como no engañarse”, sino que además nos alienta para buscar nuestro propio camino y para 
DULCE MARÍA GRANJA

pensar por cuenta propia. Por ello, Kant, lejos de ser el convidado de piedra, es el interlocutor insoslayable en la discusión filosófica de hoy.

De la misma manera como Sócrates, el más grande educador de la antigüedad, cambió por completo la faz de la filosofía con la consigna ‘Conócete a ti mismo’ que le diera el oráculo y empujó el pensamiento filosófico por la senda en la cual estamos todavía hoy, Kant modificó irreversiblemente el escenario filosófico de la modernidad y a la pregunta ¿Qué debo hacer? responde: “Atrévete a pensar por cuenta propia y sé plenamente tú mismo”.

\section{II}

\section{¿Qué es el idealismo trascendental?}

\section{El sistema}

Kant fue uno de los filósofos que elaboraron grandes sistemas en la filosofía moderna; y uno de los más difíciles problemas con los que nos encontramos al tratar de explicar un sistema es cómo escoger el punto de partida para comenzar la explicación, pues cualquier cosa que escojamos presupone otra cosa. Por eso creo que es importante tratar de remontarnos a lo que considero que fue la preocupación más amplia y fundamental de Kant y que verdaderamente dio lugar a todo su sistema filosófico, que se conoce bajo el nombre de 'idealismo trascendental'.

Según vimos en la sección anterior, Kant cultivó cuidadosamente dos de los dones filosóficos más grandes y fundamentales que un filósofo puede tener. El primero de esos codiciados dones fue su gran capacidad para descubrir un problema intelectual en donde nadie era capaz de verlo, de identificarlo en algo que hasta entonces se había considerado poco importante. El otro de esos dones fue su extraordinaria capacidad para hacer que una enorme cantidad de elementos encajen orquestadamente, de manera armoniosa, integral, 'holística', 
como suele decirse hoy en día. Lo más parecido a una integración sistemática es el ser vivo. En ese sentido, podríamos decir que la filosofía kantiana es una filosofía 'viva', i.e., una filosofía que refleja la tensión y equilibrio propios de los seres vivos. ${ }^{17}$

Ese talento para reconocer y resolver problemas hace que la posición filosófica kantiana se caracterice por tratar de mediar y conciliar los grandes debates intelectuales de su tiempo. Tomemos, por ejemplo, el primero de todos sus libros titulado Pensamientos sobre la verdadera noción de las fuerzas vivas, obra que Kant publica en 1749 cuando apenas cuenta 25 años. En esta obra el filósofo intenta arreglar el desacuerdo existente entre Descartes y Leibniz.

Recordemos que Descartes había definido la sustancia de modo meramente negativo como aquello que no depende de otra cosa para existir y que no logró ofrecer un fundamento sólido acerca del conocimiento del mundo externo. Las dos substancias finitas, lo extenso y lo pensante, permanecen sin contacto, como un dualismo entre lo espiritual y lo material, entre el cuerpo y el alma, dualismo en el cual no se ve cómo el alma pueda mover al cuerpo sin que se explique de qué modo se articula una sustancia con la otra. En el Tratado de las pasiones Descartes analiza la comunicación de lo espiritual con el cuerpo, intentando explicar por qué el hombre no es un mero mecanismo. Descartes se refiere a la glándula pineal como un órgano de función desconocida que puede mover el cuerpo desde la voluntad, pero reconoce la imposibilidad de explicar la evidente comunicación. A pesar de que la idea misma de lo extenso, como idea geométrica, supone la existencia de un espacio físico exterior a la conciencia, Descartes no prueba la existencia del espacio externo real más allá de la idea geométrica misma de lo extenso. Así, la metafísica cartesiana no logra aclarar de qué modo se produce la ‘comunicación’ entre las substancias y se hunde

${ }^{17}$ En varios lugares Kant señala la semejanza entre un sistema filosófico (concretamente el que él propone) y los seres vivos, véase por ejemplo: KrV, A833/B861; A834/B862; A836/B865. También Crítica de la razón práctica, Ak. Aug., V, 10; Prolegómenos, Ak. Aug., IV, 349-350. 
DULCE MARÍA GRANJA

en un solipsismo de la razón, en un escepticismo acerca del mundo exterior.

Leibniz, por su parte, rectifica la noción de mundo como simple extensión introduciendo la noción de fuerza o conatus en primer plano y convirtiendo la física estática en dinámica. Frente a la geometría analítica, que se deriva de la concepción cartesiana de extensión, surge el cálculo infinitesimal de Leibniz que supone la existencia de 'fuerzas' en el espacio. Descartes omite la noción de fuerza por considerarla una idea oscura y confusa, limitándose a utilizar el cálculo operatorio o aplicación del análisis a figuras geométricas, sirviéndose únicamente de lo que para él son ideas claras y distintas. Leibniz se opone a esa visión cartesiana de la realidad como algo meramente extenso, ya que, según él, no es posible concebir una realidad sin el elemento dinámico. El cálculo infinitesimal permite la medición de las variaciones y el desarrollo del movimiento, la fuerza, la dirección y la materia. Así, sostiene que no hay una radical separación entre extensión y pensamiento, ya que ambos elementos se identifican en un tercero que es síntesis de éstos y que resuelve la antinomia existente entre el cuerpo y el espíritu: la fuerza. Para Leibniz la fuerza constituye la base de toda cosa y toda materia, y éstas no han de explicarse mecánicamente sino mediante razones espirituales e inmateriales. Además, la fuerza idéntica en el fondo, se diversifica en un número infinito de objetos diferentes; cada objeto esconde una fuerza absolutamente particular que lo constituye como individuo y que no es otra cosa que su forma misma, su esencia, la fuente de la que brota su peculiar orientación y desarrollo.

La forma explica la profunda y verdadera naturaleza de cada cosa. Para Leibniz todas las cosas son sustancias idénticas y al mismo tiempo específicas, es decir, son 'formas originarias'; la genuina originalidad radica en la diferencia de las formas y la forma brota del fondo mismo de cada cosa pues no es sino la esencia de ésta. Ahora bien, para Leibniz todo ser actúa ininterrumpidamente y en él no hay jamás un reposo absoluto. La fuerza y la forma en continuo desarrollo, apuntan a una finalidad que no es algo más que la realización perfecta de cada ser. 
DOSSIER

Dicha realización es el ejercicio de la actividad propia de cada ser. En la ejecución de tal actividad cada ser manifiesta y representa la armónica perfección del universo y expresa su propio ser. Así pues, para Leibniz el universo rebosa de fuerzas y formas que obedecen a una finalidad que las armoniza entre sí, creándose la unidad dentro de la variedad. El universo está compuesto de un número infinito de fuerzas espirituales activas que se desenvuelven armoniosamente según las leyes de la continuidad y la jerarquía. Cada cosa es un individuo, una fuerza viva, un punto de energía, una sustancia viva en permanente esfuerzo vital. Esto es lo que Leibniz designa con el nombre de mónada. Así pues, el universo todo es una grandiosa obra estética que impone en nosotros la respetuosa admiración de lo sublime.

El intento kantiano por conciliar las posturas de Descartes y Leibniz era tan audaz, sobre todo para un joven autor de apenas 25 años, que inspiró a Lessing, un poeta cuatro años menor que el filósofo, un verso un tanto burlón que decía así:

Kant emprende una ardua tarea para instruir al mundo: valorar las fuerzas vivas, olvidándose de calcular las propias.

Posteriormente, en los escritos que elabora en la década de 1750 a 1760 Kant intenta avenir el choque doctrinal entre la física de Newton y la metafísica de Leibniz. En términos generales, podríamos decir que el sabio de Königsberg buscaba una síntesis que permitiera resolver la controversia entre racionalismo y empirismo y que preservara los logros definitivos que había alcanzado cada una de las dos partes contendientes.

Sin embargo, esto no significa que la filosofía de Kant sea un mero sincretismo, una conciliación mal hecha de doctrinas filosóficas totalmente disidentes entre sí. El idealismo trascendental está lejos de ser una síntesis mal lograda, una mera superposición y fusión de doctrinas discordantes. Por el contrario, Kant generó un gran avance en 
DULCE MARÍA GRANJA

filosofía pues el progreso en esta disciplina consiste en la creciente precisión con la que se formula un problema, es decir, en la relación completa de dicho problema con todos los implicados, pero que no por ello se identifican con el mismo. El progreso en filosofía permite atacar problemas cada vez más complejos, identificando lo específico de un problema pero sin desvincularlo de todos aquellos otros con los cuales está relacionado.

Esto exige no privilegiar un sistema filosófico sobre otro y más bien partir del supuesto según el cual la filosofía es una tarea permanente de apertura y síntesis, y eso fue precisamente lo que llevó a cabo el pensador de Königsberg. En efecto, creo que la preocupación más amplia y fundamental de Kant fue la de tender puentes, la de crear vínculos, la de recuperar y asimilar nuevas formas de pensamiento. Ello lo llevó a concebir la filosofía como una especie de red neuronal, como un ejercicio crítico permanente de integración y síntesis.

¿Qué es el idealismo trascendental?, dice la pregunta que da título a esta conferencia. Para iniciar a responderla echaré mano de una comparación. Imaginemos un pescador que lanza su red al mar y que al sacar los pescados encuentra que todos son mayores de diez centímetros. El pescador podría concluir que en el mar no hay más que pescados mayores a diez centímetros de longitud. Pero una conclusión más razonable o reflexiva sería que la red está tejida con aberturas de diez centímetros y que por ello no puede capturar un solo pescado menor a esa medida.

En esta analogía, la red es la mente, los pescados son la naturaleza o la realidad, y a nosotros nos toca averiguar qué relación hay entre la red y los pescados. En otras palabras, tenemos que ver cuáles son las posibilidades de la mente humana para conocer la realidad. El idealismo trascendental es la reflexión racional sobre las posibilidades de la mente para ver qué conexión tiene ésta con el mundo real.

Tratemos de precisar con más detalle los elementos que entran en juego en esta analogía. 
- La red es la mente.

- El tejido o la malla de la red es la estructura cognitiva o condiciones epistémicas del sujeto. El tejido de la red, usando las palabras técnicas del vocabulario kantiano, son las 'condiciones a priori' del conocimiento.

- La pesca es lo que capturamos, lo que aprehendemos, lo que conocemos (la naturaleza).

- La diferencia que hay entre peces y pescados es que los peces están libres en tanto que los pescados están sujetos por la red, están bajo la red. Estos últimos se consideran referidos a la red, los primeros en cambio, se consideran sin referencia a ella.

- Los pescados son lo que conocemos de la realidad. Usando nuevamente las palabras técnicas del vocabulario kantiano, los pescados son lo 'fenoménico'. Ahora bien, no podemos pescar sin red, esto significa que nuestro conocimiento siempre es fenoménico, es decir, que todo lo que conocemos lo conocemos gracias a que está referido a la red, pues la estructura de la red es la estructura de la experiencia. En otras palabras: es absurdo pretender conocer al margen de las condiciones que hemos estipulado como condiciones que hacen posible el conocimiento. El idealismo trascendental es el catálogo de todas esas condiciones epistémicas o condiciones a priori, condiciones que hacen posible nuestro conocimiento de la realidad.

Sin embargo, el que nuestro conocimiento sea fenoménico no significa que no conozcamos con verdad o que la genuina realidad nos permanezca desconocida. Haciendo un juego de palabras, podríamos decir que el verdadero conocimiento es conocimiento de lo verdadero, que el auténtico conocimiento es conocimiento de lo auténtico y que el conocimiento real es conocimiento de la realidad.

Si al decir que nuestro conocimiento es fenoménico estuviéramos queriendo dar a entender que no podemos conocer la verdad, que no conocemos más que lo aparente, lo ilusorio y lo falaz, puesto que la auténtica realidad de lo que las cosas son en sí nos permanece desconocida, 


\section{DULCE MARÍA GRANJA}

estaríamos interpretando el idealismo trascendental como una forma de escepticismo y esto es un craso e injustificable error. ${ }^{18}$ Notemos, pues, que el idealismo trascendental no está afirmando la existencia de dos tipos de realidades ontológicamente distintas, como a veces se ha interpretado equivocadamente, a saber, el mundo de los fenómenos y el mundo de las cosas en sí, el mundo de lo conocido y el mundo de lo incognoscible.

He dicho que el idealismo trascendental es el catálogo de las condiciones epistémicas. En este catálogo hay que mencionar, primeramente, la espacialidad y la temporalidad como condiciones a priori de la sensibilidad; en segundo lugar las categorías o condiciones a priori del entendimiento y, finalmente, las ideas de la razón. Ahora bien, estas condiciones epistémicas no deben confundirse con las condiciones psicológicas o condiciones empíricas del conocimiento. Las condiciones epistémicas son condiciones a priori, es decir, independientes de la experiencia y, por ello, no empíricamente determinables. Son condiciones que manifiestan la espontaneidad o actividad propias del sujeto y que cada facultad de éste produce desde sí misma.

Kant no cayó en la confusión de identificar condiciones psicológicas y condiciones a priori del conocimiento e insistió en la distinción entre quaestio facti y quaestio juris (cuestiones de hecho y cuestiones de derecho). La distinción, heredada de Leibniz, entre verdades de hecho y verdades de razón, es re-elaborada y transformada por Kant en la distinción entre quaestio facti y quaestio juris y propuesta como respuesta a Hume para quien no hay más que verdades de hecho y quien no ve un paso de lo analítico a lo sintético.

${ }^{18}$ Esta interpretación se remonta hasta los contemporáneos de Kant como Pistorius, Eberhard, Jacobi, Maimon, Aenesidemus-Schulze y Garve-Feder. Kant mismo responde a ella en sus Prolegómenos, Ak. Ausg., IV, 372-380. Más recientemente esta interpretación ha sido defendida por H. Prichard y P. Strawson. Una crítica rigurosa y aguda hacia esta interpretación convencional que hace de Kant un escéptico puede verse en el libro de Henry E. Allison, El idealismo trascendental de Kant, una interpretación y defensa, 1992, Barcelona, Anthropos, p. 29-44. 
Detengámonos brevemente en esta importante distinción entre condiciones psicológicas y condiciones epistémicas del conocimiento para señalar que las condiciones epistémicas no son otra cosa que las funciones de la estructura cognitiva del sujeto y que dicha estructura es dinámica, funcional, operativa, activa, sintética.

Así, la sensibilidad pura, nuda, pone desde sí la espacialidad y la temporalidad como formas constitutivas de ella y con las cuales ordena y arregla el material que ha recibido del mundo externo; el entendimiento saca de sí mismo sus conceptos a priori que no son otra cosa que las leyes que rigen en su funcionamiento y con las cuales dispone y acomoda la información procedente de la sensibilidad; la razón pura, nuda, suministra las ideas, con las que esta facultad organiza y sistematiza el conocimiento proveniente del entendimiento.

Así pues, estas condiciones a priori nos manifiestan qué posibilidades tiene la mente para conocer, nos permiten determinar las reglas y los límites del uso de nuestras facultades y nos permiten responder a la pregunta ¿qué puedo conocer?, una de las tres preguntas a las que debe responder el idealismo trascendental.

Quizá el rasgo más importante del idealismo trascendental sea su insistencia en señalar este carácter activo, espontáneo, dinámico del sujeto. En contraste con la pasividad de la experiencia, el sujeto es constructor del objeto de conocimiento y dicta a la naturaleza sus leyes.

En efecto, no hay percepción sensible del hecho mismo de asociar sino que llegamos a la noción de asociación por medio de la reflexión, la cual es un pensar activo, espontáneo. Igualmente, nos formamos creencias en virtud de un pensar activo y espontáneo pues la creencia no es algo que pueda originarse en la pasividad de la experiencia.

He dicho que el rasgo más importante del idealismo trascendental es el destacar el carácter activo, espontáneo y dinámico del sujeto pues en dicho rasgo radica lo que suele llamarse 'revolución copernicana' introducida por Kant en la filosofía. ${ }^{19}$ Sin embargo, debe decirse que Kant nunca se refirió a su propia filosofía como una ‘revolución’. Él

${ }^{19}$ Véase $K r V$, B XVI-XVII. 
DULCE MARÍA GRANJA

fue más moderado y modesto y la llamó simplemente una 'inversión’ en la cual se hace un ensayo, una prueba, un tanteo, para ver si desde la nueva perspectiva se consiguen explicar los problemas que no podían ser resueltos por la vieja metafísica. Estos problemas son cuestiones que la razón no puede rechazar por haber sido planteados por ella misma, pero a las que tampoco ha podido responder por sobrepasar sus fuerzas o capacidades. Así, al abordar tales problemas la razón humana ha caído en un campo de batalla de inacabables disputas, un combate donde ninguno de los contendientes ha logrado jamás conquistar el más pequeño terreno ni fundar una victoria duradera. ${ }^{20}$

Así pues, usando un ejemplo o ilustración concreta, podríamos decir que el idealismo trascendental se nos presenta como un 'pagaré', como una 'letra de cambio’ con la que Kant se compromete a pagar, es decir, a 'liquidar' los problemas insolutos (las deudas) de la vieja metafísica, puesto que Kant se atreve a decir ${ }^{21}$ que con su propuesta no hay un solo problema metafísico que no haya quedado resuelto o del que no se haya ofrecido al menos la clave para resolverlo. Estos problemas son, según veíamos en la sesión pasada, los últimos a los que el ser humano renunciaría, ${ }^{22}$ pues se trata de aquéllos frente a los cuales todos los demás poseen el valor de simples medios, son los problemas que constituyen el objetivo final de la razón. Por ello, frente a los mismos no podemos contentarnos con un saber aparente, con una respuesta que luego pueda ser rebatida y que nos conduzca a ese campo de batalla de inacabables disputas que ha sido la metafísica. Ante tales problemas, la razón exige que sean resueltos a entera satisfacción suya. ${ }^{23}$ Ese saber aparente vendría a ser, usando las palabras del propio Kant, como una mercancía de contrabando, es decir, una mercancía sin garantía, que no puede ser puesta a la venta ni aun al precio más bajo. Ese aparente

${ }^{20} \mathrm{Cfr} . \mathrm{KrV}$, B XV.

${ }^{21}$ Cfr. KrV, A XIII.

${ }^{22} \mathrm{Cfr} . K r V$, A XI.

${ }^{23}$ Cfr. KrV, A XIII. 
saber es una mercancía prohibida, que no es segura y que debe ser confiscada porque carece de factura que la respalde, que la garantice. ${ }^{24}$

Pero notemos que 'liquidar’ no sólo significa pagar, sino también ‘ajustar cuentas’. Así pues, con esta ‘letra de cambio’ Kant busca tanto garantizar las pretensiones legítimas de la razón como terminar con sus arrogancias infundadas. Y ésta es, precisamente, la doble tarea de la Crítica de la razón pura. ${ }^{25}$ Así pues, el idealismo trascendental es una crítica de las facultades humanas en general en relación con los conocimientos a los que pueden aspirar prescindiendo de la experiencia para decidir cuáles son las fuentes, la extensión y los límites del conocimiento humano.

Ahora bien, Kant no sólo desarrolló el papel que juega la crítica en el ámbito de lo teórico, del conocimiento humano, sino que también la refirió a lo práctico, al ámbito del obrar humano. Yo no examinaré aquí el papel de la crítica en el ámbito de lo teórico y me limitaré a señalar, a grandes rasgos, el papel que ésta juega en el al ámbito práctico del obrar humano.

\section{Conciencia reflexiva y proceso humanizador.}

Kant es uno de los filósofos que más ha insistido en la importancia de la capacidad crítica como uno de los elementos que intervienen de manera crucial en quien decide emprender la labor educativa. Kant ha descrito cuidadosamente en qué consiste la tarea crítica de la filosofía, en qué medida puede contribuir a la formación del alumno con inteligencia crítica y cómo puede ser enseñada la actividad filosófica entendida como tarea crítica. El pensador de Königsberg considera que el enfoque crítico o escrutinio racional es la característica suprema de la actividad filosófica, lo cual, desde luego, no excluye otras funciones características de la filosofía. Kant señala que las tesis filosóficas han de ser conside-

${ }^{24}$ Cfr. KrV, A XV y B295.

${ }^{25}$ Cfr. KrV, B XXIV-XXV. 
DULCE MARÍA GRANJA

radas, fundamentalmente, por su capacidad para ser discutidas con instrumentos racionales y para resistir esa discusión crítica. El desarrollo de la actividad filosófica depende, esencialmente, del papel de los argumentos racionales en las pretensiones de solución de un problema. Por ello esta actividad crítica ha de ser permanente y ha de considerarse que cualquier tentativa de solución tiene un carácter limitado.

Para Kant la enseñanza y ejercicio de la actividad crítica es, por antonomasia, enseñanza y ejercicio de la actividad filosófica. Esto significa que la enseñanza de la filosofía implica, desde luego, transmisión de información, i.e., enseñanza de los hechos históricos acerca del ejercicio mismo de la actividad filosófica y de las reglas que operan en tal ejercicio y fungen como parámetros de calificación. Podría decirse que este conocimiento es al filósofo como el dominio del instrumento es al artista. Es decir, se trata de la destreza en ciertas rutinas, de la habilidad que genera el entrenamiento en el manejo de una técnica.

Pero si bien este conocimiento (o talento) es condición indispensable, no puede decirse, en ningún sentido, que equivale a saber hacer filosofía. La actividad crítica, al igual que la actividad artística, es una actividad creativa. Quien en verdad hace filosofía, hace una tarea nueva, original, propia; va al fundamento y, poniendo el signo de interrogación lo bastante profundo, se pregunta por él. Entonces los viejos problemas quedan asumidos bajo nuevas perspectivas y se formulan nuevos planteamientos: problemas distintos que no pueden resolverse por medio de fórmulas estereotipadas; antes bien, ha de hacerse avanzar la capacidad lingüística, ha de crearse un lenguaje nuevo, ${ }^{26}$ más preciso y rico, que nos permita abordar de manera consistente los nuevos problemas, incluyéndolos en la totalidad del sistema y vinculándolos con los restantes elementos.

Esta sugerente conexión entre actividad crítica y enriquecimiento de la capacidad lingüística que nos propone Kant, ha de ser entendida en el

${ }^{26}$ Cfr. Crítica de la razón práctica, Ak. Ausg., V, 10. Esta conexión entre avance de la capacidad lingüística y avance del conocimiento en su integración sistemática puede verse también en Prolegómenos, Ak. Ug., IV, 322-3 y 376. 
sentido de una disposición íntegra de la persona, i.e., como un hábito en el sentido platónico y aristotélico del término: como una forma de virtud. Así, la conciencia crítica es una forma de virtud, a saber, la virtud del autodominio mediante la razón, ${ }^{27}$ que se ejerce, específicamente, sobre la pasión que el ser humano tiene por la certidumbre, la cual no es pasión por la verdad, sino por la seguridad que da la creencia de poseer la verdad. En este punto puede trazarse una importante conexión que va desde la tradición filosófica de la antigüedad y que, pasando por Kant, llega hasta el pensamiento de contemporáneos nuestros como Wittgenstein. Creo que éste es el sentido del célebre aforismo de sus Bemerkungen fechado entre 1939 y 1940, según el cual no se puede decir la verdad cuando no nos hemos dominado a nosotros mismos; sólo puede decirla quien descansa en ella, no quien todavía descansa sobre la falsedad. Por esto el trabajo en filosofía es el trabajo en uno mismo, en la propia comprensión: es la voluntad de descender al interior de uno mismo y saber lo que uno es. Por ello también podría decirse, siguiendo nuevamente a Wittgenstein, que "nunca es grande quien se desconoce a sí mismo: quien se engaña”.

Para Kant éste precisamente es el momento de madurez de la conciencia crítica, el momento de la mayoría de edad, de la autonomía, de todo el que se ha atrevido a pensar por cuenta propia: sólo cuando somos capaces de realizar una reflexión autónoma logramos afirmar nuestra identidad. Éste es el momento en el que, para Kant, el proceso educativo ha logrado su meta.

Otro aspecto estrechamente vinculado con esta conexión entre conciencia crítica e identidad que acabo de mencionar es el desarrollo moral del individuo (o de la sociedad). Incluso me parece que en este punto el pensamiento de Kant debe interpretarse como sosteniendo un paralelismo o correspondencia entre conciencia crítica y reflexión autónoma, por una parte, y conciencia crítica y desarrollo moral, por la otra.

${ }^{27}$ Cfr. KrV Ak. Ausg., A840/B868. 
DULCE MARÍA GRANJA

Según este punto de vista, las opciones de orden práctico han de estar apoyadas con argumentos racionales. Esto significa que lo único que hace posible el desarrollo moral de un individuo o de una sociedad es la reflexión que cuestiona y evalúa los principios mismos de la moralidad, las formas de vida, los valores y los sistemas de normas transmitidos a través de la tradición. Ahora bien, esto implica admitir la tesis según la cual el tratamiento de problemas morales no es posible sin el compromiso previo con algunos principios o ideas de naturaleza moral. Esta tesis concierne no sólo a la mera reflexión del discurso crítico sino, señaladamente, a la práctica.

Así pues, podría decirse que la propuesta kantiana de enlace entre desarrollo moral y afirmación de la identidad supone la posibilidad de un discurso práctico de orden racional. Dicho discurso habrá de salvar dos grandes escollos. En primer término, habrá de apartarse de la postura que subraya la importancia de los contenidos en la educación moral descuidando el aspecto de la experiencia humana en que se han originado, la historia en la que se encarnan. En segundo lugar, deberá evitar otra forma no menos empobrecida de educación moral que, en oposición a la anterior, supone que ésta es un tipo de experiencia desprovista de todo contenido.

En efecto, la comprensión de los principios morales es inseparable de las formas de experiencia moral, pues en toda acción racional está implícita una evaluación y no existe, por así decirlo, una evaluación 'primigenia' que no tenga que dar cuenta y razón de sí mediante su enlace con principios generales o ideales de vida. Así pues, Kant nos muestra que es sólo el esfuerzo por crear un discurso práctico de orden racional en el que se reconozcan las complejidades de la vida moral lo que permite el desarrollo de la identidad moral del individuo.

En correspondencia con la reflexión autónoma que, como se ha dicho, no puede consistir en la mera destreza en el manejo de información, el discurso práctico de orden racional sobre el que descansa la enseñanza moral, no se reduce a impartir información acerca de ciertos principios. Describir o explicar asuntos morales, cuando se trata de enseñar a otra persona, no es algo que pueda hacerse de la misma 
manera que cuando se describe o se explica una disciplina científica. Usando una metáfora podría decirse que jamás nadie se ha llegado a embriagar por muy a fondo que estudie la composición química del vino. La vía de 'conocimiento' en la que se apoya la enseñanza moral es una vía distinta. Una 'enseñanza' de este tipo debe basarse en un grado considerable en el ejemplo. Y así como no puede enseñarse por separado información y habilidad, tampoco puede usarse el ejemplo separado de aquélla. Cuando el maestro corrige los ejercicios del aprendiz de filosofía, ejerce la actividad crítica y al hacerlo da ejemplo, subrayando con gestos y expresiones laterales lo que considera de interés. Y el alumno descubre en el ejemplo, no tanto un modelo a seguir sino más bien su propia disposición particular para exigir, en otros casos, los requisitos que la crítica demanda en cualquier ejercicio.

En correspondencia con esto, en el discurso práctico racional, el ejemplo lo constituye el ser humano libre, cuya forma de vida nos hace descubrir la condición de posibilidad de la identidad personal y de la autonomía. Recordando aquel pequeño fragmento fechado en 1937 de las Bemerkungen de Wittgenstein, podría decirse: "Es imposible escribir sobre uno mismo con más verdad de la que uno es. Ésta es la diferencia del escribir sobre uno mismo y sobre objetos externos. Se escribe sobre uno mismo tan alto como se está. No está uno sobre zancos o en una escalera, sino sólo sobre los pies.” 
